\title{
Good Practices in School to Educate Critical Citizens. The Youth Parliament programme from the perspective of secondary school teachers in training*
}

\author{
Olga Moreno-Fernández ${ }^{1, \dagger}$, María Puig-Gutiérrez ${ }^{1}$, and José González-Monteagudo ${ }^{1}$ \\ ${ }^{1}$ Faculty of Education Sciences, University of Seville, Spain
}

\begin{abstract}
This paper refers to the European project Erasmus + ELEF (European Learning Environment Formats for Citizenship and Democracy, Reference number 580426). The aim of this project is to develop, implement, evaluate and replicate democratic and innovative learning environments (good practices) in both educational institutions and informal and community learning environments. In this context, over the course of a year, a number of experiences considered relevant have been selected, which constitute the sample of this research on good practices. This contribution presents the educational programme "Youth Parliament". This is a project with a long history and whose main objective is to train responsible citizens, with the collaboration of various educational agents. The evaluation carried out by the Secondary Education teachers in training on the potentialities and limitations of the programme is shown, based on the experiences carried out in the participating educational centres during the academic year 2016-2017.
\end{abstract}

\section{Introduction}

In Spain, due to the various changes in educational matters in recent years, education for citizenship has been contemplated in different ways according to current educational laws. Thus, with the advent of the LOE (Organic Law of Education) in 2006, education for citizenship became a compulsory and evaluable subject within the school curriculum, at the same time that it was considered a cross-cutting issue and was considered as one of the socalled basic competencies (social and citizenship competence), introduced in this law. The political changes that took place brought about reforms in the educational field and so in 2012 there was a change in the name of the subject and the contents dealt with in it.

Subsequently, with the entry into force of the LOMCE (Organic Law for the Improvement of Educational Quality) in 2013, the subject of Citizenship Education is eliminated as a compulsory subject in the curriculum, being relegated to an optional

\footnotetext{
* This paper refers to the European project Erasmus + ELEF (European Learning Environment Formats for Citizenship and Democracy, Reference number 580426).

$\dagger$ Corresponding author: omoreno@us.es
} 
subject, alternative to religion, called Social and Civic Values. It is thus maintained as a cross-cutting theme and the name of basic social and civic competence is also changed. The competences are now referred to as key competences and what we are dealing with is called social and civic competences.

In short, we have experienced a process of loss of value in education for citizenship, a fact that comes into conflict with what is happening in Europe. We must not lose sight of the fact that education for citizenship is a concern at European level and this is reflected in the various reports drawn up in recent years by the European Commission [1], [2], [3]. In its conclusion, it states that "citizenship education is one of the main means by which European countries help young people acquire the social and citizenship skills they will need in their future lives" ([2]), all of this by focusing on four specific fronts: the presence of citizenship education in school curricula; democratic culture in schools; leadership of management teams and teacher training; and assessment of learning and monitoring by the authorities.

Since the European project Erasmus + ELEF (European Learning Environment Formats for Citizenship and Democracy), which aims to implement, develop, evaluate and replicate different formats of innovative democratic learning environments (good practices), various experiences have been selected over more than a year as a sample of this research on good practices.

In this regard, we present the experience gained with the educational programme Youth Parliament, a project that has a long history and aims to train responsible citizens with the collaboration of various educational agents. To this end, we have worked with students who are doing the Master's Degree in Secondary Education (MAES) at the University of Seville (Spain), in this academic year 2017/2018.

\section{Method}

Forty-three students participated in this experience. In the experimentation carried out, the Youth Parliament Programme was presented, later analysing in small groups the formative actions carried out by the different municipalities participating in the 2016/17 academic year. These training actions were analyzed on the basis of the information contained in the worksheets that each center sends to the coordinating administration of the program, once the course is over. For the analysis, a script of questions was designed to allow future teachers to reflect on various elements that appeared in the cards.

Questions such as: What relevance does democratic citizenship have to work?, What possibilities and limitations do you consider the experience to have?, What problems have been worked on?, What kind of activities have been carried out?, Which are the bodies involved?, Do you think that this programme really favours the development of participatory and democratic citizenship in schools?, Why?

In this way, four discussion groups were organized, from the analysis of which it can be deduced that the Youth Parliament program, despite being considered an educational program that favors good citizenship education practices, presents limitations such as the number of school-age participants that can be part of it or that the themes can sometimes deviate from relevant socio-environmental issues focused on what citizen education should respond to.

\section{Results}

The results obtained in the discussion groups show us that most of the participants consider the Youth Parliament programme to be a useful programme, of great relevance for working 
on democratic citizenship, since it favours the participation of young people in the exercise of citizenship and brings them closer to making decisions on real problems in their environment. Therefore, we take as examples the following phrases:

"We believe that this is a project of great importance since it will introduce young people to citizen political participation, which should be one of the objectives of citizenship training, creating citizens with a vocation for citizen participation" (subject 6)

"Very relevant because it puts into practice the exercise of citizenship at an early age, introducing adolescents to the real functioning of public institutions" (subject 12)

Among the main possibilities that the participants highlight in the program, are to give voice to young people who, due to their minority, are not usually heard in the political arena and therefore offer them the opportunity to intervene in the life of their municipality. It also emphasizes learning to exercise citizenship and participation. Let us look at some examples:

"I believe that this is a programme with great development possibilities, since it encourages young people to participate in the life of their municipality, which is the most immediate and can be a good stimulus to awaken interest in participation" (subject 10)

"It facilitates the teaching of education for citizenship in a practical way" (subject 4)

In spite of the possibilities attributed, the participants also pointed out various limitations of the programme, among which the following stand out: "the scarce training of teachers to carry out this type of initiative, the complex network of relations between the agents involved, the scarce number of students directly involved, the dependence on the police will of the mayors and the maintenance of the current parliamentary democratic model, in which direct participation is limited to only a few".

When asked about the problems that had been worked on in the various projects analyzed, they were mentioned: lack of knowledge of the culture and customs of the local environment, help and solidarity among neighbors, healthy lifestyle habits, reading habits, creation of leisure spaces for young people, among others. Having explained the problems, the participants on several occasions showed their rejection of the idea that some of them were not directly related to relevant socio-environmental issues that responded to what education for citizenship really is. Thus, one of the subjects stated:

"There are issues that are not related to education for citizenship and that we should not consider relevant socio-environmental problems" (subject 3)

The next issue addressed concerns the type of activities carried out, including gymkhana-type activities, games, sports activities and workshops. For the development of these activities and the proper functioning of the project, various actors are involved. Thus, when the participants were consulted by the agents involved in the different projects, in almost all of them, together with the educational centre and the families, local businesses and associations and the town councils were involved. In addition, on some occasions, other larger-scale entities such as La Caixa took part in the development of the projects.

The participants are asked whether they really consider that the projects they have analysed favour the development of participatory and democratic citizenship in schools. The answers are mostly negative, since despite having initially highlighted the possibilities 
of the youth parliament programme, they believe that the concrete projects they have analysed are somewhat far removed from the socio-environmental problems relevant to the development of a critical citizenship.

Finally, each working group was asked to draw or draw a diagram on a piece of cardboard on what characteristics a program should have in order to be considered a good educational practice that favors democratic and citizen values. A work that was put in common and in which there were many coincidences. The words that represented it were: social values, equality, participation, critical reflection, freedom of expression, dialogue...Some examples of the works presented by the participants are presented below (Figures 1and 2).

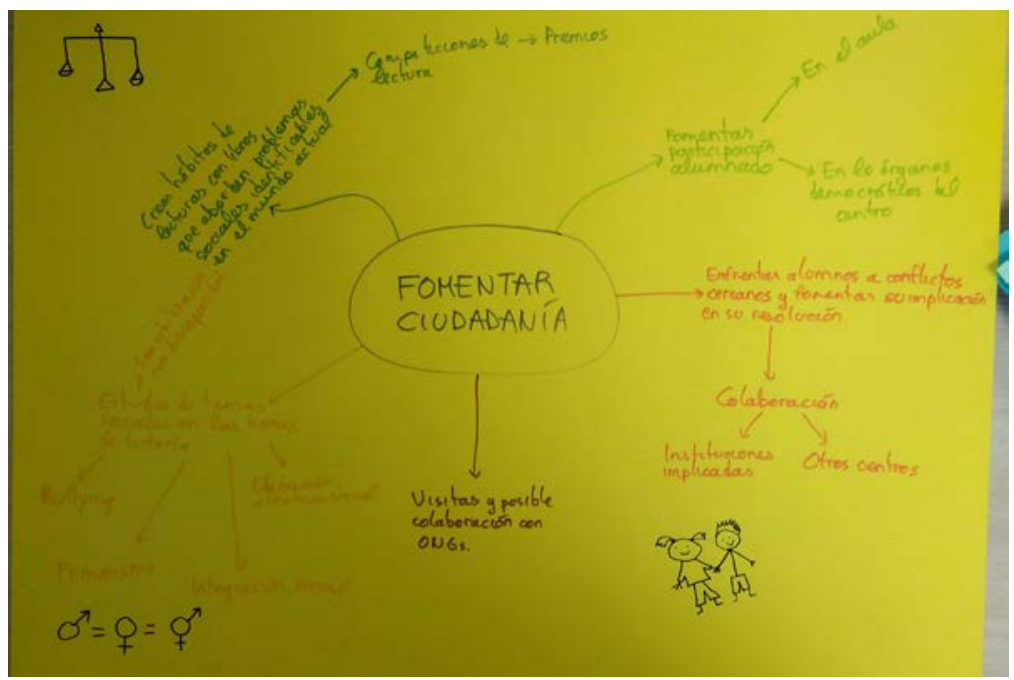

Fig. 1. Mural "Promoting citizenship". Authors: Students participating in the IDA format of the Erasmus+ ELEF programme (Reference number 580426).

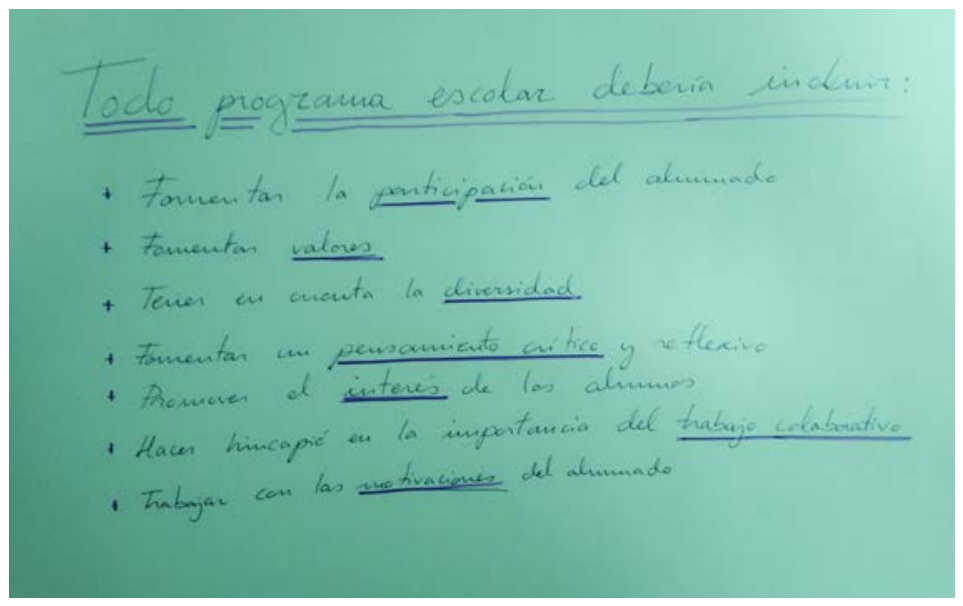

Fig. 2. Mural "Good practices". Authors: Students participating in the IDA format of the Erasmus+ ELEF programme (Reference number 580426). 


\section{Conclusion}

Analyzing the data, it is observed that the teachers in participating training value positively the need to educate responsible and critical citizens in the classroom, as well as to approach good practices that are being carried out in schools. With this experience, the future teachers of Secondary Education have been given the opportunity to approach the reality of the centers and programmes that are being carried out successfully. This first contact made it possible for them to reflect on the importance of having good educational practices for civic education in the classroom.

\section{References}

1. Eurydice Report, Education for citizenship in the European school context (Brussels, European Commission, 2005)

2. Eurydice Report, Education for citizenship in Europe (Brussels, European Commission, 2012)

3. Eurydice Report, Citizenship education at school in Europe (Brussels, European Commission, 2017) 